\title{
OPORTUNIDADES EMPRESARIAIS NO SECTOR DO TURISMO EM REGIÕES DO INTERIOR DE PORTUGAL ${ }^{*}$
}

\begin{abstract}
Manuela Ribeiro
O turismo nas regiões do interior, embora ainda muito incipiente, revela, ao longo dos nos últimos anos, índices ineludiveis de crescimento das suas principais componentes, a saber - procura, oferta, emprego, investimento, entre outros.

Neste contexto, o turismo aparece mesmo como um dos mais, senão mesmo o mais importante instrumento de multiplicação de oportunidades empresariais nestas regiões, tendo em conta o seu carácter de actividade multifacetada e as interdependências que mantém com praticamente todos os outros sectores da economia; as tendências de crescimento da procura e, acima de tudo, o estádio ainda relativamente embrionário da oferta regional e local.

Partindo da identificação dos principais campos aonde se situam tais oportunidades, neste artigo são desenvolvidas algumas considerações de carácter eminentente prático, acerca da concretização das mesmas.

Palavras - chave: regiões do interior, turismo, oportunidades empresariais.
\end{abstract}

** Professora Associada de Sociologia do Departamento de Economia e Sociologia da UTAD, Vila Real. 


\section{INTRODUÇÃO}

Nos últimos quinze anos, as regiões do interior têm vindo, gradualmente, a integrar a geografia do turismo em Portugal, a exemplo, aliás, do que se regista por toda a Europa.

A conversão destes territórios em destinos turísticos tem decorrido da convergência de uma série de factores, dos quais, desde logo, cabe destacar as novas motivações que se têm vindo a desenhar e a consolidar no campo da procura turística, os novos interesses, expectativas e preocupações que elas veiculam, os novos valores que as inspiram e orientam. O quadro das novas tendências da procura vem, efectivamente, dando passo à descoberta de elementos de atracção turística em regiões do interior, em regiões desfavorecidas, ou seja, em regiões sem praticamente nenhuns antecedentes na campo do turismo.

Esta reorientação da procura no sentido de destinos alternativos aos clássicos de "sol e praia" e de "cidades" tem, de resto, sido abundantemente usada pelos poderes públicos como principal justificação do papel activo e decisivo que vêm assumindo no incremento do turismo nestas regiões.

Com efeito, entre os responsáveis políticos aos mais diversos níveis da Administração Pública, tem vindo a crescer a convicção de que o turismo, pelas suas características, pode constituir a turbina do processo de construção de respostas para os extensos e graves problemas socioeconómicos que estas regiões vêm desde, há muito, acumulando, e que são, em boa parte, problemas gerados e ampliados pelo desinteresse e a omissão desse mesmo poder político.

Dando sequência e corpo a tal convicção, as instâncias governamentais - comunitárias, nacionais e locais - têm vindo a adoptar posturas abertamente proactivas e voluntaristas no sentido de estimular, criar condições, apoiar e intervir no fomento do turismo nas regiões do interior. São indicadores significativos do empenho que a Administração Pública vem pondo neste objectivo, as iniciativas legislativas de enquadramento e regulamentação de actividades e de definição de produtos; os apoios financeiros ao investimento directo e indirecto no sector, disponibilizados através de uma vasta panóplia de programas, para referir apenas os mais impactantes.

Como corolário do duplo processo que resumidamente deixámos exposto, o turismo nas regiões do interior, embora ainda muito incipiente, revela, ao longo dos nos últimos anos, índices ineludíveis de crescimento 
das suas principais componentes, a saber: procura, oferta, investimento, etc.

Neste contexto, o turismo aparece mesmo como um dos mais senão mesmo o mais, importante instrumento de multiplicação de oportunidades empresariais nestas regiões, tendo em conta o seu carácter de actividade multifacetada e as interdependências que mantém com praticamente todos os outros sectores da economia, bem como as tendências de crescimento da procura e, acima de tudo, o estádio ainda relativamente embrionário da oferta regional e local.

Analistas, operadores, agentes privados e públicos e, sobretudo, turistas coincidem largamente no reconhecimento de que o turismo no interior comporta e exige espaços ainda muito consideráveis para a criação e expansão de iniciativas empresariais que, por um lado, complementem, modernizem e diversifiquem a oferta regional existente e, por outro, promovam e concretizem a valorização de recursos endógenos de evidente potencial económico.

A abordagem que aqui desenvolveremos sobre novas oportunidades empresariais ligadas ao turismo, desdobrar-se-á pelos seguintes pontos:

- Aspectos a considerar na identificação de subsectores e de actividades aonde existem/podem existir as ditas oportunidades;

- Identificação de tomadores (particularmente vocacionados) para as acolher;

- Meios de apoio disponíveis para as concretizar;

- Elementos a ponderar nas iniciativas individuais;

- E, por último, aquilo que consideramos ser a outra face das oportunidades empresariais, ou seja, o quadro real de constrangimentos e de entraves de diversa índole que pesam sobre a concretização e a sustentabilidade das mesmas.

Não podendo, por razões óbvias, aqui tratar exaustivamente cada uma destas vertentes e as interrelações que as percorrem, limitar-me-ei a apresentar algumas reflexões soltas e parciais sobre estas matérias, reflexões que me têm sido suscitadas pelo trabalho de investigação em que tenho colaborado ao longo dos últimos anos, sobretudo em Trás os Montes e Alto Douro, mas também noutras áreas do interior, como o Parque Natural da Peneda-Gerês. 


\section{ASPECTOS A CONSIDERAR NA IDENTIFICAÇÃO DE SUBSECTORES E DE ACTIVIDADES ONDE EXISTEM/PODEM EXISTIR AS DITAS OPORTUNIDADES}

Por se tratar de sector que só recentemente arrancou, a oferta turística nas regiões do interior, além de escassa, tende a ser qualitativamente débil, o que, em conjunto, configura a existência de múltiplas oportunidades de negócio e de criação de emprego. Tais oportunidades emanam directamente da necessidade de colmatar lacunas, quase sempre bastante grandes, existentes ao nível das componentes mais convencionais da oferta - alojamento, restauração, transportes, etc. - e preencher valências que começam agora a emergir: novas práticas desportivas, de fruição da natureza e de animação em geral.

Uma terceira área, com evidentes potencialidades no campo empresarial, é a que recobre as chamadas actividades de suporte (M. Ribeiro e C. Marques, 2000: 3), designadamente, actividades inerentes à necessidade dum conjunto de serviços que suportem a expansão das empresas turísticas. Como exemplos de serviços abrangidos por este subsector, podem referir-se: o recrutamento e a formação dos recursos humanos, o marketing, desde os estudos de mercado ao desenvolvimento de imagem, as actividades ligadas à gastronomia, desde o estudo e desenvolvimento de receitas regionais até ao fornecimento dos produtos tradicionais, e várias outras actividades de suporte, nomeadamente no campos editorial, da gestão e da tecnologia.

No desenho das iniciativas concretas que podem dar corpo a estas novas oportunidades empresariais, a procura deve, obviamente, ser tomada como referência central, por forma a que os produtos e as actividades sejam concebidos e desenvolvidos para mercados minimamente bem definidos. Conhecer melhor as suas expectativas e exigências ajudará a oferta a adaptar-se à procura, melhor dito, às especificidades dos segmentos que nela predominam.

Mas o conhecimento dos turistas, dos principais traços do seu perfil e das tendências do seu comportamento constitui, também, uma referênciaorientadora fundamental para a oferta poder adoptar atitudes e medidas mais activas. É o caso, por exemplo, dos dados sobre as visitas dos turistas às regiões do interior que, ao mostrarem que as mesmas se concentram nos meses de Verão e correspondem, por regra, a estadias curtas - fins-de-semana, "pontes", etc -, imediatamente deixam a descoberto a necessidade de arquitectar e levar à prática produtos e fórmulas que permitam dilatar a temporalidade das estadias e distender o 
calendário das visitas, como condições necessárias a uma maior eficiência económica do sector.

Por outro lado, o estudo de clientes, reais e potenciais, é também a base para a construção de ofertas autónomas e inovadoras, como as que podem ser dirigidas a segmentos da procura ainda muito desatendidos pela oferta existente, pela oferta convencional, como é o caso dos deficientes, dos reformados, de alguns tipos de enfermos, de jovens, etc.

Mas, para além da satisfação das necessidades e desejos, implícita ou explicitamente apresentados pelos turistas, à oferta abre-se ainda a possibilidade altamente aliciante, mas também bastante mais arriscada e muito mais exigente, de produzir respostas para necessidades que ela mesmo cria e que, enquanto tal, são novas e desconhecidas dos turistas. É que, como afirma Jorge Micele, um autor argentino (1993: 179), "el descubrimiento de las nuevas necesidades, deseos o expectativas de los turistas, es un campo, casi ilimitado".

Esta citação coloca-nos directamente no terreno do último aspecto que seleccionei para tratar neste ponto. Trata-se da importância da criatividade, da imaginação, do engenho, para "descobrir" e, muito especialmente, para realizar e dar vida às oportunidades empresariais que o turismo nas regiões do interior é capaz de propiciar.

A incorporação obrigatória da criatividade nestes processos é, antes de mais, uma condição necessária à salvaguarda de uma maior capacidade afirmativa e competitiva das empresas, em primeiro lugar, mas também de cada uma destas regiões, face a outras com ofertas turísticas semelhantes, por ser certo que, cada vez mais as correntes turísticas, emanando essencialmente das zonas urbanas, procuram o que é diferente e genuino: diferente por não ser urbano, genuíno por não ser possivel encontrar idêntico noutro local (H. T. Marques, 88:24.Sublinhado nosso).

Ser criativo, no tipo de serviços e produtos oferecidos aos turistas e na forma como os mesmos são prestados, contribuirá, decisivamente, para potenciar a originalidade da oferta regional.

\section{TOMADORES PARA AS ACOLHER}

Diversos estudos realizados em diferentes países mostram que não é, de todo, automática a relação entre a emergência de oportunidades empresariais no campo do turismo em regiões do interior e o aparecimento de tomadores para as mesmas, sobretudo de tomadores 
locais e/ou regionais. Estes são, consensualmente, considerados e eleitos como os tomadores ideais, por razões que facilmente se intuem, e que vão da maior garantia que teoricamente representam, em termos de captação e retenção local das mais-valias geradas pelo negócio, ao melhor conhecimento que detêm da região, dos seus recursos, das suas limitações e por consequência, de um maior compromisso relativamente ao entorno físico, social e cultural em que operam.

Todavia e, devido aos processos de erosão social e de elevado desgaste demográfico que sofreram durante as últimas décadas e que as foi progressivamente privando de capacidade de iniciativa, de dinamismo, de força anímica, de auto-confiança, de capacidade empreendedora, estas regiões vêm demorando a responder aos novos desafios que o turismo lhes coloca, cedendo, deste modo, espaço à eventual instalação de agentes exteriores.

Realizando importantes transfusões e transferências de contactos, conhecimentos, saberes e capitais a favor destas regiões, estes agentes, vindos de fora, desempenham / podem desempenhar um papel muito importante na dinamização social e económica das mesmas. São, no entanto, muito insistentes as advertências e as chamadas de atenção feitas, nomeadamente por instâncias supragovernamentais como a OCDE (1994: 28), acerca dos potenciais aspectos negativos que podem ir associados com a exterioridade dos tomadores. Citem-se, a título de exemplo, a sua mais reduzida sensibilização à cultura local, às suas tradições, usos e costumes; a mais elevada probabilidade de recorrerem a fornecedores externos e de retirarem para fora da região os lucros e ganhos da actividade desenvolvida; a ausência de "lealdades" para com a região, que mais facilmente abandonarão se acharem que as condições para o negócio deixaram de lhes interessar, etc.

Ainda a propósito das novas oportunidades empresariais que se desenham no campo do turismo, é plausível admitir a existência de tipos específicos de tomadores, às quais elas poderão, por diferentes razões, ser mais favoravelmente ajustadas. Estarão, neste caso, as mulheres, os jovens, os agricultores e os reformados "enxutos".

As mulheres, porque um grande número de tarefas, directa e indirectamente ligadas ao acolhimento e atendimento de turistas, se inscreve numa linha de continuidade linear com a que os padrões vigentes de divisão do trabalho, por sexos, lhes atribui, quase a título de exclusividade. A este respeito, vale a pena citar aqui um estudo da OCDE (P. Munheim, 1995:48), aonde se salienta que, embora a presença das mulheres no emprego turístico geral seja muito variável de país para país, 
em todos eles, as mulheres representam a mais elevada percentagem do emprego turístico das regiões rurais. E em Portugal há também números, como os relativos à titularidade dos empreendimentos Turismo em Espaço Rural (TER), que apresentam uma significativa taxa de feminização. As mulheres representam cerca de $45 \%$ do total dos titulares formais das unidades de alojamento TER, licenciadas pela Direcção Geral do Turismo ${ }^{1}$.

Estes valores percentuais são, por si mesmos, bastante sugestivos quanto ao dinamismo e ao protagonismo que as mulheres portuguesas vêm detendo nas actividades de acolhimento turístico em espaço rural, uma situação que é, de resto, comum a muitos outros países (G. C. Valiente e M ${ }^{\mathrm{a}}$ D. Garcia Ramon, 1995; M. Bouquet e M. Winter, 1987).

Por serem detentores de recursos, materiais e imateriais, grandemente significativos no contexto da actual procura turística das regiões do interior, os agricultores perfilam-se, pelo menos teoricamente, como agentes bem posicionados para tomarem iniciativas empresariais relacionadas com o turismo, desde o alojamento á animação e a produtos conjugados. E, no mesmo plano argumentativo, cabe igualmente dizer-se que o turismo se posiciona como uma oportunidade aliciante para aliviar o quotidiano dos agricultores dos múliplos problemas que o constrangem.

Deve, no entanto, ressalvar-se que, como a experiência vem mostrando, os agricultores resistem bastante à exploração de oportunidades ligadas ao turismo. A maioria deles, se pudesse escolher, preferiria certamente melhores preços para os produtos agrários do que incentivos para divergir para o turismo. Esta resistência por parte dos agricultores tem, segundo alguns estudos (OCDE, 1994: 31), muito a ver com a sua falta de conhecimentos e de treino em assuntos de turismo, o que, necessariamente, lhes imporá inibições e receios, tanto mais compreensíveis e racionais, quanto é certo que a grande maioria dos agricultores nunca teve qualquer contacto com o sector, nem sequer como consumidores.

Mas as novas oportunidades empresariais que se desenham no sector ligado ao turismo inscrevem-se, em grande parte, no âmbito das chamadas actividades de animação, um campo que recobre possibilidades extremamente variadas, desde as actividades de ar livre ligadas ao desfrute, ao conhecimento e á observação da Natureza; aos desportos mais ou menos radicais, e a todo um vasto leque de práticas com graus de aventura e risco mais ou menos acentuados. Pelas suas próprias características, e porque, no geral, são moderadamente exigentes em termos de investimento e o seu funcionamento é, na maior parte dos 
casos, compatível com estruturas leves e flexíveis, estas áreas de actividade são particularmente apelativas para os mais jovens. E como mostram as escassos dados existentes sobre o assunto, são exactamente os mais jovens que respondem pela grande maioria das iniciativas empresariais que neste campo se têm vindo a desenvolver, um pouco por todo o país.

E, finalmente, uma breve referência ao que designei como "reformados enxutos", indivíduos que se retiram da actividade profissional principal a que dedicaram uma vida de trabalho, em condições etárias e de saúde suficientemente satisfatórias para se envolverem em projectos que lhes preencham o tempo liberto, lhes realizem sonhos e aspirações antigas e lhes rendibilizem os patrimónios imobiliários e financeiros que possam ter angariado. Respaldados por rendimentos seguros das pensões e de outras fontes, as actividades empresariais que, até agora, mais os têm cativado são as do alojamento de TER, onde aparece em número considerável e ao serviço do qual põem importantes talentos: conhecimentos sobre a história, a cultura a etnografia das suas regiões; grandes disponibilidades de tempo para o atendimento personalizado dos seus clientes; as capacidades e as habilidades de relacionamento social apuradas ao longo de dezenas de anos de exercício profissional, etc.

Estas e outras características específicas deste segmento de tomadores podem ser eficazmente postas a "render" em alternativas de outro tipo, como as que compreendem dimensões pedagógicas - circuitos e iniciativas de interpretação da Natureza, do património cultural, etc., quintas pedagógicas, por exemplo - ou alternativas associadas a memórias e saberes do passado: produção e comercialização de produtos alimentares tradicionais, organização integrada de provas dos mesmos, etc.

\section{OS MEIOS DE APOIO DISPONÍVEIS PARA AS CONCRETIZAR}

Quem se disponha a ponderar e/ou a decidir-se pela instalação ou pelo alargamento de uma empresa em qualquer subsector da oferta turística em regiões do interior tem, quase de certeza, ao seu dispor algum meio, algum instrumento geral ou específico de apoio financeiro a que recorrer. Não vou, obviamente, deter-me aqui nos detalhes funcionais ou administrativo-burocráticos, por regra complexos e pesados, que qualquer 
deles envolve, pois para isso estão / devem estar os Gabinetes de Apoio ao Investidor instalados nas Regiões de Turismo, as Associações de Desenvolvimento, as Associações Socioprofissionais, as Autarquias e outros organismos de implantação local e regional.

Limitar-me-ei, neste ponto, a referenciar alguns dos mais importantes, como os estabelecidos no âmbito do Programa Operacional da Economia (POE), a saber: o SIPIE (Sistema de Incentivos a Pequenas Iniciativas Empresariais), o SIME (Sistema de Incentivos à Modernização Empresarial), e o recentemente regulamentado SIVETUR (Sistema de Incentivos a Produtos Turísticos de Vocação Estratégica), de grande aplicabilidade nas zonas de interior, em particular das que integram Espaços Naturais Protegidos (ENP's). Fora destes, e criados também ao abrigo do actual Quadro Comunitário de Apoio, existem outros, como o SAJE (Sistema de Apoio a Jovens Empresários), e o LEADER + (Iniciativa Comunitária de Desenvolvimento Rural).

Sobre esta relativa abundância de meios financeiros para apoio a iniciativas empresariais, não posso deixar de reiterar a chamada de atenção que vem sendo feita, sobre o carácter excepcional que a sua disponibilzação assume, face às mudanças no Orçamento Comunitário previstas para depois de 2006. Com efeito, e por razões que não vou aqui analisar por serem do conhecimento geral, é seguro admitir que o período de vigência do actual Quadro Comunitário de Apoio (2000-2006) representará um tempo crucial e, quiçá, irrepetível, de oportunidades a aproveitar para desenvolver o sector e, com ele, as regiões e o país.

Esta constatação representa um enorme desafio para as regiões do interior, como Trás-os-Montes e Alto Douro. Em primeiro lugar, porque em matéria de turismo (como noutras), têm muita coisa por fazer e, em segundo, porque se o quiserem fazer, têm obrigatoriamente de adoptar ritmos de concretização comparativamente mais acelerados.

\section{OS ELEMENTOS A PONDERAR NAS INICIATIVAS INDIVI- DUAIS}

A eficácia e a sustentabilidade das iniciativas empresariais, sobretudo em áreas tão novas como as que vão ou podem ir associadas ao processo de desenvolvimento do turismo em regiões do interior, exigem uma séria ponderação prévia dos diferentes factores - pessoais e contextuais - que informam e enformam os projectos concretos. As oportunidades 
empresariais turísticas em espaços do interior, sendo grandes e reais, são também e nas palavras de um autor francês (V. Daniel, 1995: 82) oportunidades "a bien mesurer". Ou seja, ainda segundo outro autor da mesma nacionalidade (F. Moinet, 2000: 107), antes de agir, é preciso saber porquê e como.

Num domínio como o turismo, onde as possibilidades de escolha são numerosas, o enquadramento institucional e legislativo bastante complexo e o mercado mutante, é essencial que os projectos de instalação ou de diversificação se conduzam com base numa reflexão consciente $\mathrm{e}$ segundo metodologias de rigor.

Sem outras pretensões que não as de alertar para a importância fundamental desta questão, diremos, em termos muito sucintos, que tais requisitos implicam um método de acção, concretizável através de um percurso, em regra demorado, ao longo do qual se deverão achar e clarificar respostas a uma série de interrogações e intrepelações, a propósito do projecto particular que se pretende desenvolver. As principais etapas deste percurso podem ser assim esquematizadas:
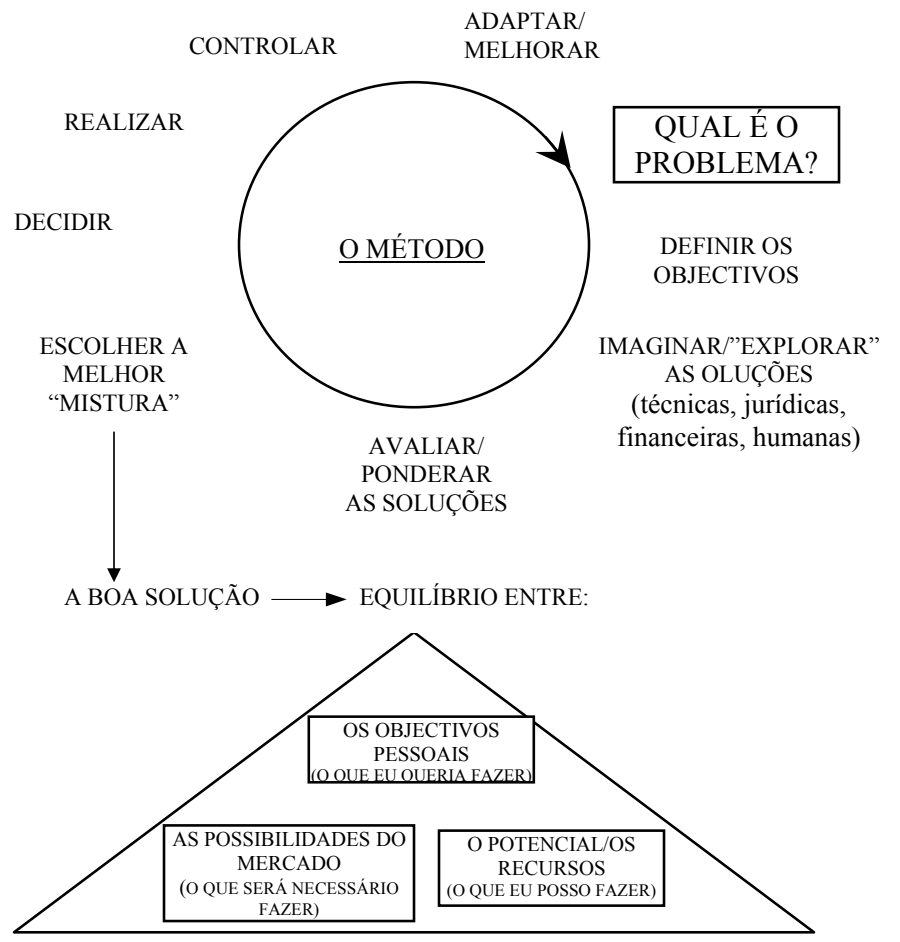

(Adaptado de F. Moinet, 2000: 108). 
Num relance, mesmo breve como o que aqui se poderá fazer deste percurso como um todo e de cada uma das etapas que o compõem, claramente se visualiza o forte apelo que ele faz a informação muito diversificada: sobre o mercado, os consumidores, segmentação da procura, o seu perfil, a legislação, fiscalidade, investimentos em capital, em trabalho, sobre formas de promoção, etc. $\mathrm{O}$ volume da informação necessária tende, muito frequentemente, a ultrapassar as capacidades e as possibilidades individuais, o que torna imprescindível a existência e o acesso a meios de apoio técnico-económico, os chamados serviços de consultoria e de assessoria, capacitados para ajudarem os eventuais interessados a concretizarem os seus projectos com a máxima segurança possível, o mesmo é dizer, com riscos tão reduzidos quanto possível.

\section{O QUADRO REAL DE CONSTRANGIMENTOS E DE ENTRAVES DE DIVERSA ÍNDOLE QUE PESAM SOBRE A CONCRE- TIZAÇÃO E A SUSTENTABILIDADE DAS INICIATIVAS EMPRESARIAIS}

A existência de novas oportunidades empresariais no campo do turismo nas regiões do interior vai, como é de todos sabido, acompanhada pela existência de muitos factores e situações que cerceiam e entravam o desenvolvimento das mesmas. São, efectivamente, muitos e muito "resistentes", os constrangimentos que, nestas regiões, rodeiam a iniciativa empresarial em geral e, portanto, também no turismo.

Boa parte desses factores limitantes decorre e é reflexo das debilidades e dos estrangulamentos que compõem a situação de atraso e de perificidade que genérica e persistentemente tem caracterizado as regiões em apreço, e que, enquanto tal, projectam limitações consideráveis sobre todo o processo de desenvolvimento regional, incluindo, como é óbvio, o campo do turismo. Incluem-se, neste grupo, as insuficiências e carências que aparecem, muitas vezes, designados como "entraves estruturais" (CCRN, 99.72), e que, entre outros, recobrem domínios como os que a seguir se indicam:

capital humano: rarefacção demográfica e empresarial da região; mão de obra pouco qualificada; reduzida capacidade de iniciativa e um diminuto espírito empresarial, fraca capacidade de investimento, técnica e de gestão; 
infra-estruras e equipamentos : baixa qualidade de acessibilidades intra $\mathrm{e}$ inter-regionais, de meios de transporte e de sistemas d comunicação, de equipamentos desportivos, culturais e de lazer, para mencionar apenas os mais citados;

enquadramento institucional: peso excessivo de centralização institucional, burocracia, inadequação e desactualização das iniciativas, debilidades financeiras, técnicas, operacionais e funcionais das instituições regionais e locais, escassez de informação, etc.;

estética da paisagem: disfunções e degradação das paisagens natural, humana e construída;

mercados regionais/locais: de dimensão muito restrita;

distância aos centros de poder e de decisão sobretudo distância política: dependência cultural, económica e social do exterior.

Ao rol das adversidades "externas" com que se confronta o desenvolvimento da actividade turística nestas regiões, somam-se os "pontos fracos", os entraves, que têm vindo a gerar-se e a somar no interior da própria actividade. E entre estes sobressaem, desde logo, os que derivam da procura e que, no essencial, se reportam à sazonalidade $\mathrm{e}$ à temporalidade curta das estadias e aos efeitos nefastos que uma e outra impõem aos resultados da actividade.

Mas, também do lado da própria oferta turística destas regiões se regista a ocorrência de elementos susceptíveis de restringir ou mesmo comprometer o sucesso de oportunidades empresariais que se abrem nos diferentes subsectores que a integram. Estou a referir-me a aspectos que, no geral, aparecem identificados como e/ou associados com "mentalidade"; "individualismo"; défice de "sensibilização", "qualidade", "organização", "participação", "integração", "consciência", "conhecimento", "informação", "profissionalismo", "ordenamento", para mencionar apenas os mais insistentemente enunciados.

Devidamente especificados, generalizadamente reconhecidos como tais, tanto pelos analistas como pela esmagadora maioria dos agentes no terreno, os factores que actualmente limitam e/ou bloqueiam o desenvolvimento de iniciativas turísticas constituem, no essencial, um terreno eminentemente político e, no geral, de difícil intervenção. É, porém, mais do que evidente, que protelar por muito mais tempo a erradicação dos factores que mais negativamente condicionam a actividade empresarial turística significará, certamente, que muitas das novas oportunidades, de que aqui falámos, se verão irremediavelmente convertidas em oportunidades perdidas. 


\begin{abstract}
NOTAS
* Este texto corresponde a uma versão levemente revista de uma comunicação apresentada ao Seminário "Desenvolvimento Rural: Perspectivas em Debate", organizado no âmbito do Programa Delfim (Vila Real/Bragança) pela Escola Superior Agrária de Bragança, em 23 de Maio de 2001.

${ }^{1}$ Números relativos a 1997.
\end{abstract}




\section{BIBLIOGRAFIA}

ALBINO, J. e outros (2000), Turismo e desenvolvimento no Norte Alentejo. ed. Colibri, Lisboa.

BOUQUET, M. and WINTER, M. (1987), Who from their labour rest? conflict and practice in rural tourism. aldershot. avebury press.

DANIEL, V. (1995), "Entabilité des activités touristiques en millieu rural". In Agritourisme et Développement Local, Irest et Enita, Collection Actes $\mathrm{n}^{\mathrm{o}} 3$, pp 72-82.

FORUM DE TRÁS-OS-MONTES E ALTO DOURO (2000), Tema 4 - Turismo. diagnóstico e orientações prospectivas. Relatório final. Vila Real, Texto policopiado, 72 pags.

MICELE, J. E. (1993), La actividad de las empresas turisticas. Signos Universitarios, $\mathrm{n}^{\mathrm{o}} 24, \mathrm{pp} .171-182$.

MOINET, F (2000), Le tourisme rural comment créer et gérer?. Ed. France Agricole, Paris, $3^{\mathrm{a}}$ ed.

MUHEIM, P. (1995), "La contribution du tourisme au développement rural". In Agritourisme et Développement Local, Irest et Enita, Collection Actes $\mathrm{n}^{\mathrm{o}} 3$, pp 47-50.

OCDE (1994), Tourism strategies and rural development. OCDE/GD (94)49, Paris.

RIBEIRO, M. e MARQUES C. (2000), Processos emergentes de desenvolvimento do turismo em regiões do interior - pluralidade de oportunidades e de constrangimentos para empresas e empresários. Com. apresentada às IX Jornadas Luso-Galaicas de Ciencia y Desarrollo, UTAD, Chaves, 19 e 20 de Outubro.

SPIDOURO (1999), Turismo em Trás-os-Montes e Alto Douro. (Detecção de oportunidades e formatação de negócios). Vila Real, Texto policopiado, 59 pgs.

VALIENTE, G. C. e RAMON, Ma D. Garcia (1995), "Mujeres y turismo rural en Cataluña y Galicia: la nueva panacea de la agricultura?”. El Campo, 133, pp 221-237. 